\title{
Critical appraisal of the role of recombinant activated factor VII in the treatment of hemophilia patients with inhibitors
}

This article was published in the following Dove Press journal:

Journal of Blood Medicine

27 March 2010

Number of times this article has been viewed

\author{
Ampaiwan Chuansumrit ${ }^{1}$ \\ Pantep Angchaisuksiri ${ }^{2}$ \\ Nongnuch Sirachainan' \\ 'Departments of Pediatrics and \\ 2 Medicine, Faculty of Medicine, \\ Ramathibodi Hospital, Mahidol \\ University, Bangkok, Thailand
}

\begin{abstract}
Hemophilia patients with inhibitors faced the constraint of inadequate treatment for several years before the era of recombinant factor VIIa (rFVII). Initially, rFVIIa was used in the compassionate-use programs. After a worldwide license was issued, more than 1.5 million doses were administered. Bleeding of joints and muscles was controlled effectively by means of an early home treatment program, with either a standard dose of $90 \mu \mathrm{g} / \mathrm{kg}$ every 2 to 3 hours for a few doses or a single dose of $270 \mu \mathrm{g} / \mathrm{kg}$. For more serious bleeding episodes or minor surgery, an initial dose of $90 \mu \mathrm{g} / \mathrm{kg}$ was given every 2 hours for 24 to 48 hours followed by increased intervals of 3 to 6 hours according to the severity of bleeding and efficacy of bleeding control. In cases of major surgery such as orthopedic procedures, the same regimen can be applied except for a higher initial dose of 120 to $180 \mu \mathrm{g} / \mathrm{kg}$. However, increasing the dose should be considered if there are unexpected bleeding complications since the half-life and clearance of rFVIIa differ between individuals. In addition, prophylaxis is administered to a small number of patients. Finally, the reported thromboembolic events found in hemophilia patients with inhibitors receiving rFVIIa are extremely low, much less than $1 \%$.
\end{abstract}

Keywords: bleeding disorder, hemophilia, inhibitor, NovoSeven, recombinant factor VIIa

\section{Introduction}

Among patients with hemophilia, $85 \%$ to $90 \%$ have hemophilia A and $10 \%$ to $15 \%$ have hemophilia B. The risk of developing inhibitors differs; $25 \%$ to $30 \%$ of hemophilia A patients develop inhibitors to factor VIII clotting activity, ${ }^{1,2}$ while only $1 \%$ to $3 \%$ of hemophilia B patients develop inhibitors to factor IX clotting activity. ${ }^{3}$ There are two types of inhibitors: low responding and high responding. Low-responding inhibitors occur in approximately $20 \%$ to $50 \%$ of patients with hemophilia. These patient usually have inhibitor titers below 5 Bethesda units (BU) and, when re-exposed to factor concentrates, do not mount an anamnestic response. Low-responding inhibitors may be transient and disappear spontaneously. They can be treated with a higher dose of factor concentrates. However, some of these may convert to high-responding over time. Therefore, careful monitoring should be done periodically. In contrast, inhibitor levels in high responders will rise markedly after being exposed to factor concentrates. Most patients with high-responding inhibitors have titers greater than $10 \mathrm{BU}$, although if they have not been re-exposed to factor concentrates for some time, baseline titers may be lower. The treatment in these patients is more problematic. Hemophilia patients with inhibitors risk increased morbidity and mortality compared with noninhibitor patients. If inadequately treated, the frequent joint bleeds will lead to synovial inflammation and hypertrophy, and predisposition to recurrent bleeding with progressive damage to the

submit your manuscript | www.dovepress.con 
cartilage and subchondral bone. ${ }^{4}$ These patients will suffer from chronic pain requiring frequent hospital visits. They will need devices for facilitating mobility such as wheelchairs and crutches. Also, they will be absent from work and school which results in poor health-related quality of life. ${ }^{5}$

The aim of management of hemophilia patients with inhibitors is to control the bleeding episodes and to eradicate the inhibitors by immune tolerance therapy. However, immune tolerance therapy is not always successful. As a result, various elective surgeries were often delayed or canceled due to inadequate hemostatic achievement. In 1983, Hedner and Kisiel reported the successful use of human plasma derived factor VIIa in the treatment of two hemophilia patients with high-titer inhibitors. ${ }^{6}$ Subsequently, the recombinant factor VIIa (rFVIIa; NovoSeven ${ }^{\circledR}$; Novo Nordisk) was derived from cultured hamster kidney cells using recombinant DNA technology. The development of rFVIIa has opened a new era for hemophilia patients with inhibitors. It has low risk of transfusion-transmitted disease compared to plasma-derived hemostatic agent. Moreover, rFVIIa has not exhibited immunogenicity in hemophilia $\mathrm{A}$ and $\mathrm{B}$ patients. It has shown effective hemostasis during joint, muscle and soft tissues bleeding ${ }^{7}$ as well as minor and major surgeries. ${ }^{8}$ There are two mechanisms of action of highdose FVIIa: 1) tissue factor independent thrombin generation on the activated platelets, resulting in the formation of tight hemostatic fibrin plugs resistant to premature lysis, ${ }^{9}$ and 2) FVIIa overcoming competition with zymogen FVII for binding to tissue factor to form factor VIIa-tissue factor complex with subsequent activation of other coagulation factors to generate thrombin. ${ }^{10}$ The rFVIIa was used on the compassionate-use programs during 1988 to 1999 and subsequently licensed for the treatment of hemophilia patients with inhibitors in Europe in 1996, Asia in 1997 to 1998 and North America in 1999.

This paper reviews experience with rFVIIa in the treatment of hemophilia patients with inhibitors from the compassionate- and emergency-use programs and from independent published reports from 1988 to 2009.

\section{Materials and methods}

For the independent relevant publications assessed in this paper, a literature search (PubMed) from January 1988 through November 2009 was used to identify independent reports of hemophilia patients with inhibitors treated with rFVIIa. The search terms including "activated factor VII", "rFVIIa", "recombinant activated FVII", "NovoSeven" and "rhFVIIa" were used with each of the following: "hemophilia with inhibitors", "hemophilia and inhibitors to FVIII or FIX", "congenital hemophilia and inhibitors". Only English language literature was considered and publications included only those in which patients had inhibitors to factor VIII or factor IX and were treated with rFVIIa.

\section{Compassionate-use programs}

Recombinant factor VIIa was available on an emergency- and compassionate-use basis from 1988 to 1999 for the open-label treatment of hemophilia patients with inhibitors to factor VIII or factor IX for life-threatening hemorrhage and hemostasis maintenance during surgery when alternative therapies were unavailable or had already failed to stop bleeding or when complications were foreseen. The treatment was provided on a named-patient basis with a series of case reports. In most studies, the efficacy of rFVIIa in producing hemostasis was evaluated using a global assessment by the physician, the patient, or the patient's caregiver. The precise definitions used varied between trials but generally, categories such as excellent, effective, partially effective, or ineffective were included. The assessment took into account relief of pain/tenderness, improved joint mobility, size of the bleed, and/or cessation of bleeding. The overall effective response to $\mathrm{rFVIIa}$ at the dose ranging from 60 to $120 \mu \mathrm{g} / \mathrm{kg}$ after 8 and 24 hours in the first 55 consecutive bleeds was $91 \%$ and $90 \%$, respectively. ${ }^{11}$ Recombinant factor VIIa has been given since 1988 to hemophilia patients with inhibitors suffering from life- and limb-threatening bleeds in the central nervous system, intraperitoneum and retroperitoneum, as well as muscle and joint bleedings. The higher dose (around $90 \mu \mathrm{g} / \mathrm{kg}$ ) given every 2 to 3 hours was more effective than lower dosages in more serious bleeding situations. ${ }^{12}$

Data on the use of rFVIIa in the treatment of serious nonsurgical bleeding from the noncomparative compassionateand emergency-use programs have shown that the response was rated as excellent or effective in $62 \%$ to $86 \%$ of bleeding episodes following treatment with rFVIIa. ${ }^{8,13-17}$

\section{Independent published reports Efficacy of nonsurgical bleeding control}

Trials of rFVIIa in hemophilia patients with inhibitors include dose-finding studies and home treatment studies. An initial, randomized, double-blind, dose-finding multicenter study included 179 joint, muscle, and mucocutaneous bleeding episodes in 78 patients treated with two dosages of rFVIIa (35 and $70 \mu \mathrm{g} / \mathrm{kg}$ intravenously every 2 to 3 hours). It demonstrated that the two dosages were similarly effective. ${ }^{18}$ 
However, a substantial delay before start of treatment (about 7.5 hours longer in the $70 \mu \mathrm{g} / \mathrm{kg}$ group) may have contributed to the lack of difference in efficacy between the two groups. Among hemarthroses, the global response to treatment was excellent or effective in $71 \%$ of each dosage group and the mean number of doses per episode of bleeding was 3.1. Data from the compassionate-use programs suggested that a higher dose (around $90 \mu \mathrm{g} / \mathrm{kg}$ ) given every 2 to 3 hours was more effective than lower dosages in more serious bleeding situations. $^{12}$

The effect of early treatment as well as regular treatment several times per week in preventing the development of long-term arthropathy is well documented. ${ }^{19}$ Early treatment with rVIIa is more likely to be associated with a successful outcome than late treatment. ${ }^{20}$ To facilitate an early initiation of treatment, rFVIIa was studied in a home treatment setting. Recombinant factor VIIa was administered at a dosage of 90 to $100 \mu \mathrm{g} / \mathrm{kg}$ every 2 to 4 hours and treatment had to be initiated within 8 or 12 hours of the onset of bleeding. ${ }^{20-22}$ After about two doses, the hemostatic response was rated as excellent or effective in $79 \%$ to $93 \%$ of bleeding episodes. After initial resolution, bleeding recurred within 24 to 48 hours in $4 \%$ to $5 \%$ of episodes.

In one of the noncomparative home treatment studies, the risk of an ineffective or a partially effective response was significantly lower if treatment was started within 6 hours of the onset of bleeding than if it was started later (odds ratio 0.24; $95 \%$ CI $0.09,0.63) .{ }^{20}$ Combined analyses of data from a dosefinding study, home treatment study, and compassionate use study confirmed the benefits of early treatment for patients with acute hemarthrosis ${ }^{23}$ or intramuscular hemorrhage. ${ }^{24}$ Fewer doses were needed and higher response rates were achieved when treatment was initiated early. Therefore, in a home treatment setting, rFVIIa was effective in controlling mild to moderate bleeding episodes in hemophilia patients with inhibitors.

Recently, it was shown that the use of higher doses for the treatment of acute bleeding episodes, to achieve full hemostatic effect after one single dose of rVIIa, is a convenient, safe, and effective, alternative to the repeated dose regimen for hemophilia patients with inhibitors. ${ }^{25-31}$ The effectiveness of treatment with a single dose of rFVIIa $270 \mu \mathrm{g} / \mathrm{kg}$ is similar to that of a standard regimen $(90 \mu \mathrm{g} / \mathrm{kg}$ every 3 hours for 3 doses) in hemophilia patients with inhibitors experiencing hemarthroses. ${ }^{25-27}$ The outcomes were similar for the single $270 \mu \mathrm{g} / \mathrm{kg}$ dose and the standard regimen in terms of the treatment response rate, as assessed by patients after 9 hours ( 25 to $65 \%$ versus 31 to $70 \%$, respectively), and the proportion of patients not requiring additional hemostatic medication to control a bleeding episode (91\% and $92 \%$ versus $86 \%$ and $91 \%) .{ }^{25,26}$ In the open-label study, in which patients were not required to use all three doses of the standard regimen unless necessary, the median number of injections used for this regimen was three and so the median quantity of rFVIIa administered was the same as for the single-dose regimen (270 $\mu \mathrm{g} / \mathrm{kg}$ per bleeding episode). ${ }^{27}$

The use of high doses of rFVIIa is also supported by an analysis of data from a registry of hemophilia patients with inhibitors, which found that bolus doses $>200 \mu \mathrm{g} / \mathrm{kg}$ were associated with a significantly higher bleed-cessation rate than seen with lower doses (97\% of 119 bleeds versus $84 \%$ of 436 bleeds; $P<0.01) .{ }^{32}$ Successful use of bolus doses as high as $300 \mu \mathrm{g} / \mathrm{kg}$ has been reported. ${ }^{33}$

A single dose of $270 \mu \mathrm{g} / \mathrm{kg} \mathrm{rFVIIa}$ is of particular benefit for patients with poor venous access, frequent target-joint hemorrhage, and needle phobia. The single-dose treatment regimen may improve patient compliance, enhance the ease of home treatment, and facilitate earlier control of hemorrhagic events.

Two randomized, open-label, crossover studies comparing rFVIIa with activated prothrombin complex concentrates (aPCC) in the home treatment of hemophilia patients with inhibitors have been reported. ${ }^{26,34}$ Prior to these two studies, a number of studies, most of them single-arm studies and none of them directly comparing rFVIIa and aPCC, have investigated the efficacy of these two agents.

The main finding of the FENOC (FEIBA NovoSeven Comparative) study was that rFVIIa (2 doses of 90-120 $\mu \mathrm{g} / \mathrm{kg}$ ) and aPCC (1 dose of 75-100 IU/kg) appear to exhibit a similar effect on joint bleeds. ${ }^{34}$ The primary endpoint was the proportion of patients reporting effective or partially effective hemostasis at 6 hours after treatment initiation. Six hours after infusion, the rate of effective plus partially effective responses was $78.7 \%$ for rFVIIa versus $80.9 \%$ for aPCC (90\% CI $-11.4 \%-15.7 \% ; P=0.059)$. The efficacy of the two treatments was rated differently by a substantial proportion of patients at all time points up to 48 hours. The percentage of discordant pairs (one treatment effective and the other not effective) ranged from $9.8 \%$ to $43.8 \%$ at different time points, but was highest during the first 12 hours after treatment. Although the objective of this study was to demonstrate equivalence between both products, the statistical criterion to declare both products to be equivalent was not met.

In the second trial, two different regimens of rFVIIa (a single dose of $270 \mu \mathrm{g} / \mathrm{kg}$ and a regimen of 3 doses of 
$90 \mu \mathrm{g} / \mathrm{kg}$ at 0,3 and 6 hours; administered in double-blind fashion) were compared with a single dose of aPCC $75 \mathrm{IU} / \mathrm{kg}$ (administered unblinded). ${ }^{26}$ No statistically significant difference was found between treatment groups with both the binary global response algorithm $(P=0.17)$ and the trichotomous global response $(P=0.09)$. However, a trend towards increased response was observed in the rFVIIa groups compared with the aPCC group using both global responses. The proportion of patients needing additional "rescue" hemostatic therapy within the first 9 hours was also significantly lower with the single $270 \mu \mathrm{g} / \mathrm{kg}$ dose of rFVIIa treatment than with aPCC $(8.3 \%$ versus $36.4 \% ; P=0.03)$, and likewise it was lower in the standard 3-dose regimen of rVIIa compared with the aPCC group, although statistical significance was not reached $(9.1 \%$ versus $36.4 \% ; P=0.07)$.

Analysis using a unified Bayesian meta-regression model has suggested that a typical rFVIIa ( $90 \mu \mathrm{g} / \mathrm{kg}$ every 3 hours) will resolve joint bleeding more effectively than a typical aPCC regimen (75 IU/kg every 12 hours) after 12, 24 and 36 hours. $^{35}$ A systematic review of the cost-effectiveness of rFVIIa and aPCC in the treatment of minor/moderate bleeding episodes for hemophilia patients with inhibitors has also suggested that rFVIIa may be a cost-effective alternative to treatment with aPCC. In 7 of 9 studies, rFVIIa had a lower average treatment cost. ${ }^{36}$

\section{Continuous infusion of rFVIla}

Continuous rFVIIa infusion is a feasible method for the treatment of both nonsurgical ${ }^{37}$ and surgical bleeding ${ }^{38-41}$ because of its $100 \%$ stability and safety, documented by sterility for 3 days at room temperature after being reconstituted with diluents. ${ }^{42}$ The clearance of continuous rFVIIa infusion, calculated by clearance $(\mathrm{mL} / \mathrm{kg} / \mathrm{h})=$ infusion rate $(\mathrm{IU} / \mathrm{kg} / \mathrm{h}) /$ plasma level $(\mathrm{U} / \mathrm{mL})$, increases in children compared to adults and remains the same level over the time of treatment. ${ }^{43}$ The amount of $1200 \mu \mathrm{g}$ rFVIIa is equivalent to $60,000 \mathrm{IU}$. The median clearance in adults was $56 \mathrm{~mL} / \mathrm{kg} / \mathrm{h}$ and $86 \mathrm{~mL} / \mathrm{kg} / \mathrm{h}$ in children. ${ }^{44}$ Therefore, continuous rFVIIa infusion to maintain a required level depends on an individual's clearance of rFVIIa. Normally, the estimated infusion rate of $16.5 \mu \mathrm{g} / \mathrm{kg} / \mathrm{h}$ can raise the plasma level closed to $10 \mathrm{U} / \mathrm{mL}$. This level is widely considered as an acceptable minimal value to maintain hemostasis..$^{40,43,45}$ The advantages of continuous infusion included the $50 \%$ reduction of rFVIIa requirements when compared with the bolus injection and the stability of activity during infusion. ${ }^{39}$

Most of the protocols of continuous rFVIIa infusion start with a rFVIIa bolus at a dose of $90 \mu \mathrm{g} / \mathrm{kg}$ initially and every 2 hours during surgery, followed by continuous infusion to maintain a plasma level above $10 \mathrm{U} / \mathrm{mL}$. However, during the first 2 to 3 days after surgery, the level of rFVIIa was suggested to be maintained at a higher value of 24 to $56 \mathrm{U} / \mathrm{mL}$. Then, the level was gradually decreased until the suture was stitched off. The range of total treatment duration in elective surgery was reported at 1 to 34 days. ${ }^{38,41,43,44,46,47}$ The effectiveness of this treatment in a prospective cohort study, mainly of spontaneous bleeding cases, was around $80 \%$. However, the difference in response was the bleeding at the mucosal surface, found to be effective in only 1 of 7 patients. ${ }^{48}$ The difference in response was hypothesized to be due to the high fibrinolytic activity in the oral cavity, which can be counterbalanced by the activation of thrombin activatable fibrinolysis inhibitor (TAFI) stimulated by bolus injection. In patients with elective surgery, the effectiveness in controlling bleeding symptoms was around $33 \%$ to $85 \%$ depending on individual studies. Nonetheless, bleeding complications could be effectively controlled by additional bolus rFVIIa injection with the dose range of 60 to $90 \mu \mathrm{g} / \mathrm{kg}$. The difference in response was due to the types and aggressiveness of surgery, complications after surgery such as infection, the adjuvant of other hemostatic agents such as tranexamic acid and the dose of rFVIIa used during treatment (Table 1). ${ }^{37-44,46,48-50}$

To prevent unexpected bleeding, the sequential treatment with bolus and continuous infusion was successfully reported in a patient with hip arthroplasty. A bolus injection of $150 \mu \mathrm{g} / \mathrm{kg}$ was given at the start of surgery followed by $120 \mu \mathrm{g} / \mathrm{kg}$ every 2.5 hours for the first 2 days and $90 \mu \mathrm{g} / \mathrm{kg}$ every 3 hours for the third day. Then, continuous infusion was subsequently administered for the rest of the treatment course. $^{49}$

Similar to other factor concentrates, the prevention of thrombophlebitis is required. Standard heparin and lowmolecular-weight heparin (LMWH) were studied by adding to the rFVIIa solution. The result showed that the rFVIIa activity in the standard heparin mixture was decreased by $50 \%$ within 4 days. ${ }^{42,51}$ Therefore, parallel infusions of standard heparin or normal saline or adding LWMH to the mixture can be used to prevent thrombophlebitis. ${ }^{40}$

\section{Hemostasis for major surgery}

Major surgery includes exploratory laparotomy, surgery in the vital organs such as brain, heart and lungs, and orthopedic procedures of bone fixation for fractures, hip and knee arthroplasty, arthrodeses, open synovectomy, osteotomy, pseudotumor removal and hardware such as plates and intramedullary 


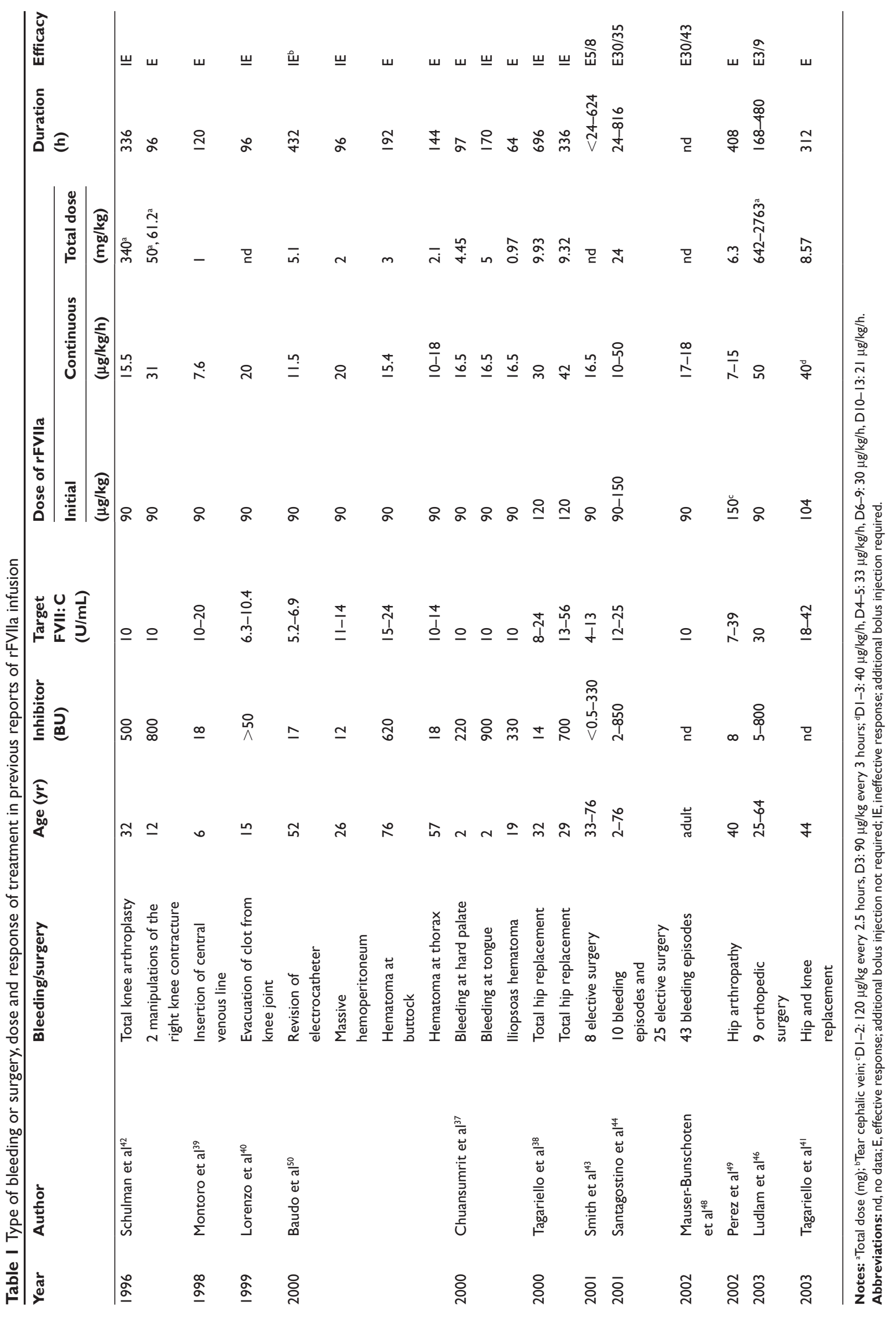


nail removal. ${ }^{52}$ The earliest major surgical procedure of an open knee joint synovectomy in a hemophilia patient with inhibitors using rFVIIa was first reported by Hedner et al in $1988 .{ }^{53}$ Ingerslev et al have shown the effectiveness of 12 hemophilia patients with inhibitors undergoing surgery by giving a mean dose of rFVIIa $99 \mu \mathrm{g} / \mathrm{kg}$ every 2 to 3 hours for up to 2 days after which dosage intervals were prolonged. ${ }^{54}$ The results revealed excellent responses in 11 cases and an effective response in one case.

A prospective, double-blind, randomized trial that compared 2 doses of rFVIIa (35 and $90 \mu \mathrm{g} / \mathrm{kg}$ ) in hemophilia patients with inhibitors who were undergoing 18 minor and 11 major surgeries was reported in $1998 .^{9}$ Bolus injections of rFVIIa were given every 2 hours for the first 48 hours. Thereafter, the same dose was given every 2 to 6 hours for an additional 3 days. A significant difference in efficacy in terms of maintaining postoperative hemostasis favoring the high-dose group was observed from day 3 onward, although both doses were similarly effective intraoperatively.

Moreover, an international series of 108 cases of elective surgeries performed in nine hemophilia centers worldwide was published in 2004 . However, only 17 major orthopedic surgeries under the cover of rFVIIa were included in the series. The outcome revealed 14 good results, 1 fair result and 2 poor outcomes. ${ }^{55}$ Furthermore, a case report ${ }^{56-58}$ and case series ${ }^{59-61}$ of major surgeries among hemophilia patients with inhibitors using rFVIIa ranging from 90 to $300 \mu \mathrm{g} / \mathrm{kg}$ every 2 hours in the first 24 hours followed by 90 to $120 \mu \mathrm{g} / \mathrm{kg}$ with prolonged intervals of 3 to 6 hours have gradually been reported, with effective response rates ranging from $66 \%$ to $100 \%$.

In 2009, a consensus protocol for the use of rFVIIa in elective orthopedic major surgeries in hemophilia patients with inhibitors was published. ${ }^{62}$ It was based on a review of published data and the personal experience of a group of expert physicians in Europe. According to the recommendations, major surgeries should be performed at a comprehensive hemophilia center with the availability of expert physicians in the morning, early in the week. Other protocols were given as follows. It is essential for the expert physicians to closely monitor the patient for a few days after the surgery. An initial bolus dose of rFVIIa in the range of 120 to $180 \mu \mathrm{g} / \mathrm{kg}$ is given at the start of surgery followed by $90 \mu \mathrm{g} / \mathrm{kg}$ at 2-hour intervals throughout surgery. A final intraoperative bolus should be given just prior to final reduction in the case of hip arthroplasty or release of the tourniquet in the case of knee arthroplasty. After 48 hours of 2-hour boluses, the dosing intervals may be increased to
3 hours for the following 48 hours and to 4 hours for the next 72 hours. At day +8 after the surgery, the intervals between doses may be lengthened to 6 hours. The topical application of a fibrin sealant during the intraoperative period is helpful in minimizing capillary oozing. Additionally, the concomitant administration of an antifibrinolytic agent such as tranexamic acid is recommended, unless there is a strong contraindication. It may enhance the effect of rFVIIa and improve hemostasis. ${ }^{51}$ In cases of bleeding complications after the surgery, the next scheduled dose of rFVIIa should be brought forward and a dose increase should be considered or an additional 5 doses of $90 \mu \mathrm{g} / \mathrm{kg}$ of rFVIIa should be given every 2 hours until the hemostasis is achieved. If the measures are not been successful, changing treatment to aPCC should be considered. Importantly, the postoperative physiotherapy should be covered by a bolus of rFVIIa. These protocols have been used in 10 major orthopedic surgeries involving 13 procedures in 5 comprehensive care centers. The intraoperative hemostasis was satisfactorily achieved; however, 2 cases were reported of postoperative bleeding. The first case had bleeding in the knee 5 days after arthroplasty. The patient did not receive tranexamic acid perioperatively and the bleeding resolved after the dose of rFVIIa was increased. The second case exhibited bleeding 8 hours after shoulder arthroplasty. The patient had received tranexamic acid and the bleeding gradually resolved 5 days after switching the treatment to aPCC. The cost of medication to cover this type of surgery was approximately US\$750,000 which is 10 times greater than that for a person without inhibitors. ${ }^{52,62}$ Although solving the problem in the target joint initially is costly, it will decrease the tendency for further frequent bleeding in that target joint and also decrease the frequency of bleeding in other joints such as the shoulders or elbows if the patient has to use crutches for the next 5 to 9 years. ${ }^{63}$

\section{Sequential/concomitant therapy of rFVIla and aPCC}

An initial strikingly excellent response of hemophilia patients with inhibitors to rFVIIa after aPCC treatment was observed by Key et al. ${ }^{64}$ The possible synergy between rFVIIa and aPCC in vivo and in vitro was demonstrated in 3 patients. It might be due to the presence of activated clotting factors in the aPCC prior to rFVIIa administration. Sequential therapy of rFVIIa and aPCC was reported among ten children who had failed their home treatment with rFVIIa and aPCC alone $(\mathrm{n}=9),{ }^{65,66}$ and refractory bleeding to the treatment of rFVIIa $(\mathrm{n}=1) .{ }^{67}$ They received alternating doses of rFVIIa (80 to $225 \mu \mathrm{g} / \mathrm{kg} / \mathrm{dose}$ ) and aPCC (35 to $80 \mathrm{IU} / \mathrm{kg} / \mathrm{dose}$ ) every 
6 hours; and 1 to 3 doses of rFVIIa were given every 2 hours between aPCC doses. Hemostasis was achieved and no thromboembolic (TE) event was detected. However, such patients should be hospitalized and under the supervision of experts in hematology to guard against the risk of TE complication. Antifibrinolytic agents should be avoided.

Recently, Martinowitz et al reported the use of concomitant infusions of low doses of rFVIIa (30 to $70 \mu \mathrm{g} / \mathrm{kg} / \mathrm{dose}$ ) and aPCC (20 to $30 \mathrm{IU} / \mathrm{kg} / \mathrm{dose}$ ) in 5 adult hemophilia A patients with inhibitors ( 8 to $1300 \mathrm{BU}$ ), aged 17 to 60 years who were refractory to rFVIIa administration. ${ }^{68}$ They exhibited a total number of 400 bleeding episodes, mainly hemarthrosis with excellent hemostasis; they required 1 dose of concomitant therapy if initiated early after onset of bleeding for 1 to 2 hours, and 2 to 3 doses daily every 6 hours for some target joints and large hematoma. The concomitant therapy every 6 hours for 24 hours followed by 3 times daily and thereafter 2 times daily for a total of 72 hours has been successfully used for papilotomy and gallbladder stent insertion. No adverse events and no disseminated intravascular coagulation were observed following these infusions.

\section{Prophylaxis with rFVIla}

Prophylaxis in hemophilia patients with inhibitors is not generally recommended due to the concern of efficacy, TE complications, and cost. The first report described the use of a daily dose of $240 \mu \mathrm{g} / \mathrm{kg}$ in a hemophilia B patient with high titers during the perioperation and postoperative intensive physical rehabilitation for the correction of a knee contracture.$^{69}$ To date, rFVIIa prophylaxis has been reported in 45 hemophilia patients with inhibitors as shown in Table $2 .^{69-75}$ Of note, 22 patients were included in a randomized, double-blind study of receiving daily prophylaxis of rFVIIa $90 \mu \mathrm{g} / \mathrm{kg}$ or $270 \mu \mathrm{g} / \mathrm{kg}$ for 3 months. ${ }^{72}$ The frequencies of bleeding episodes were significantly reduced by $45 \%$ and $59 \%$ during the prophylaxis with 90 and $270 \mu \mathrm{g} / \mathrm{kg}$, respectively $(P<0.0001)$ compared to on-demand therapy. However, no significant difference was detected between the doses. Interestingly, the reduction of bleeding episodes was maintained during the postprophylaxis period. The effectiveness of giving pharmacological doses of rFVIIa used in the prophylaxis can be explained by the hypothesis that the extravascular diffusion of rFVIIa will be available at the site of injury. It could contribute to the hemostatic plug by increasing thrombin generation on activated platelets. ${ }^{76}$

Since the frequency of bleeding episodes during prophylaxis was significantly reduced, the days of hospitalization, absences from work and school, and equipment to increase mobility were significantly reduced, which led to marked improvement of health and related quality of life compared with on-demand therapy. ${ }^{77}$ No TE complication was reported. However, the cost derived from prophylaxis is more expensive than the prior therapy with factor VIII concentrate but cheaper than the prior immune tolerance therapy.

Prophylaxis with rFVIIa is a potential option for preventing episodes of joint bleeding and protecting joint damage while awaiting a decline in inhibitor titers before immune tolerance therapy can be initiated. Moreover, an international survey of attitudes towards secondary prophylaxis with rFVIIa in hemophilia A patients with inhibitors was conducted by interviewing 31 physicians from hemophilia centers and 20 health care providers in Europe and the US. ${ }^{78}$ The results revealed a positive attitude and more support for secondary prophylaxis in children than in adults.

\section{Thromboembolic complications}

Reports on TE complications related to the use of rFVIIa in hemophilia patients with inhibitors are rarely found. From 1996 to 2003 over 700,000 doses $(90 \mu \mathrm{g} / \mathrm{kg}$ ) were given, there have been $25 \mathrm{TE}$ events found in hemophilia patients with inhibitors and acquired hemophilia patients. ${ }^{79}$ An additional 800,000 doses of rFVIIa have been administered from 2003 to 2006 during which time a total of $30 \mathrm{TE}$ events and $6 \mathrm{TE}$ event-associated fatal events occurred among hemophilia patients with inhibitors and acquired-hemophilia patients. ${ }^{80}$ Two additional studies reviewed the MedWatch pharmacovigilance program of US Food and Drug administration for TE adverse events occurring in patients administered rFVIIa in the period from April 1999 through June 2002 and from March 25, 1999 through December 31, 2004. The first study ${ }^{81}$ reported $67 \mathrm{TE}$ adverse events in rFVIIa recipients compared to 16 events in aPCC $\left(\right.$ FEIBA $\left.^{\circledR}\right)$ recipients in hemophilia patients with inhibitors and acquired hemophilia patients. The incidence rate ratio of 2.98 (CI 1.71-5.52) suggested the higher TE occurrence in rFVIIa than aPCC recipients. The second study ${ }^{82}$ reported 185 TE events described in 168 reports. One hundred and nine reports described TE events occurring mainly in unlabeled uses for bleeding in nonhemophilia patients $(\mathrm{n}=92)$ and occurring less often in hemophilia patients $(n=17)$. Additional 59 reports described TE events occurred in nonhemophilia patients enrolled in postlicensure trials of unlabeled uses. The TE events involved cardiovascular accidents $(n=39)$, acute myocardial infarction $(n=34)$, other arterial thromboses $(n=26)$, pulmonary embolism ( $\mathrm{n}=32$ ), other venous thromboses including deep vein thrombosis $(n=42)$, and clotted devices $(n=10)$. 
Table 2 Patient characteristics, regimen, duration and number of bleeding at pre-prophylaxis and prophylaxis period

\begin{tabular}{|c|c|c|c|c|c|c|c|c|}
\hline \multirow[t]{2}{*}{ Year } & \multirow[t]{2}{*}{ Author } & \multirow{2}{*}{$\begin{array}{l}\text { Hemophilia } \\
\text { A/B (case) }\end{array}$} & \multirow{2}{*}{$\begin{array}{l}\text { Inhibitor } \\
\text { (BU) }\end{array}$} & \multirow{2}{*}{$\begin{array}{l}\text { Age } \\
(y r)\end{array}$} & \multirow{2}{*}{$\begin{array}{l}\text { Dose of } \\
\text { rFVIla }\end{array}$} & \multirow[t]{2}{*}{ Duration } & \multicolumn{2}{|c|}{ Number of bleeds } \\
\hline & & & & & & & Pre-prophylaxis & Prophylaxis \\
\hline \multicolumn{9}{|c|}{ Secondary prophylaxis } \\
\hline 2001 & $\begin{array}{l}\text { Cooper } \\
\text { et al }{ }^{69}\end{array}$ & $B(I)$ & 12.9 & 13 & $\begin{array}{l}240 \mu \mathrm{g} / \mathrm{kg} \\
\text { every } 6-24 \mathrm{~h}\end{array}$ & 80 days & $\mathrm{a}$ & $2 / 80$ days $^{\mathrm{b}}$ \\
\hline 2001 & $\begin{array}{l}\text { Saxon } \\
\text { et al }{ }^{70}\end{array}$ & $A(I)$ & 16 & 4 & $90 \mu \mathrm{g} / \mathrm{kg} / \mathrm{d}$ & 21 weeks & 2.1/week & $0.4 /$ week \\
\hline \multirow[t]{2}{*}{2005} & $\begin{array}{l}\text { Young } \\
\text { et } \mathrm{al}^{71}\end{array}$ & $A(I)$ & I.I-2.5 & 3 & $\begin{array}{l}200 \mu \mathrm{g} / \mathrm{kg} \\
\text { every } 6-8 \mathrm{~h}\end{array}$ & 12 months & $32 / 14$ months & $7 / 12$ months \\
\hline & & $B(I)$ & $50-100$ & 15 & $\begin{array}{l}200 \mu g / k g \\
\text { every } 12 \mathrm{~h}\end{array}$ & 25 months & $2.2 /$ month & $0.8 /$ month \\
\hline \multirow[t]{3}{*}{2007} & $\begin{array}{l}\text { Konkle } \\
\text { et } \mathrm{a}^{72}\end{array}$ & $\begin{array}{l}A(I 0), \\
B(I)\end{array}$ & $>2$ & $<18(\mathrm{n}=9)$ & $90 \mu \mathrm{g} / \mathrm{kg} / \mathrm{d}$ & 3 months & $5.6 /$ month & $3.0 /$ month \\
\hline & & & & $>18(n=2)$ & & & & \\
\hline & & $A(I I)$ & $>2$ & $\begin{array}{l}<18(n=7) \\
>18(n=4)\end{array}$ & $270 \mu \mathrm{g} / \mathrm{kg} / \mathrm{d}$ & 3 months & $5.3 /$ month & $2.2 /$ month \\
\hline 2007 & $\begin{array}{l}\text { Morfini } \\
\text { et } \mathrm{al}^{73}\end{array}$ & $\begin{array}{l}A(12), \\
B(I)\end{array}$ & $>5$ & $\begin{array}{l}<18(n=10) \\
>18(n=3)\end{array}$ & $\begin{array}{l}200-250 \mu \mathrm{g} / \mathrm{kg} / \\
\text { week to } \\
220 \mu \mathrm{g} / \mathrm{kg} / \mathrm{d}\end{array}$ & 4-48 months & $0.25-8.33 /$ month & $\begin{array}{l}0-2.25 / \\
\text { month }\end{array}$ \\
\hline \multicolumn{9}{|c|}{ Primary prophylaxis } \\
\hline 2008 & $\begin{array}{l}\text { Jimenez-Yuste } \\
\text { et } \mathrm{al}^{74}\end{array}$ & $A(I)$ & 9.4 & 3 & $90 \mu \mathrm{g} / \mathrm{kg} / \mathrm{d}$ & 15 months & $3 / 3$ years & I/I5 months \\
\hline 2009 & $\begin{array}{l}\text { Jimenez-Yuste } \\
\text { et } \mathrm{al}^{75}\end{array}$ & $A(5)$ & $11-440$ & 2 & $90-100 \mu g / k g / d$ & 9 months & $4 / 2$ years & I/9 months \\
\hline
\end{tabular}

Notes: ${ }^{a}$ Wheelchair-bound with bilateral knee contracture of 30 degrees; ${ }^{\mathrm{b}}$ Traction and casting/wedging procedures were successfully achieved with only 2 trauma-related bleeding episodes.

Seventy-three (52\%) of 144 patients with time information in the first 24 hours after the last rFVIIa infusion for which 30 events occurred within 2 hours. Limited data were available for concomitant risk factors and the underlying medical conditions of the patients, which complicates the analysis. Nevertheless, the average risk of a TE event was approximately 3.75 per 100,000 infusions. ${ }^{80}$ The majority of events were found in off-label use and with concomitant hemostatic agents such as the sequential use of rFVIIa and aPCC. ${ }^{83}$ Ultimately, the incidence of TE events with the use of rFVIIa in hemophilia patients with inhibitors was extremely low, much less than $1 \%$, and appeared unrelated to dose. No TE event was ever found in any hemophilia patient receiving a single high dose of $270 \mu \mathrm{g} / \mathrm{kg}$ of rFVIIa.

For continuous infusion, the dose is lower than that of bolus injection; therefore, the activation of the hemostatic system would be less than that of the bolus injection. The activation of hemostasis was demonstrated in 4 patients receiving continuous infusion over 4 to 18 days. The prothrombin fragments $(\mathrm{F} 1+2)$ and D-dimer were increased after bolus injection and unchanged throughout the treatment period of continuous infusion without clinical thromboembolism. ${ }^{50}$

\section{Discussion}

The development of inhibitors to factor VIII and factor IX is one of the most challenging complications found among hemophilia patients. Less than optimal treatment and lack of prophylaxis lead to chronic arthropathy, deformity and early death. Elective and orthopedic corrective surgeries are often delayed or canceled due to the difficulty in achieving hemostasis. Prior to 1988, the only available factor concentrate was aPCC. Although aPCC is effective in controlling bleeding episodes and achieving hemostasis for surgeries, the reported number of major surgeries is relatively minimal. The discovery of plasma derived factor VIIa and rFVIIa has opened a new era for hemophilia patients with inhibitors to have treatment similar to those without inhibitors.

The initial constraints of rFVIIa are its short half-life and dose-finding. From compassionate-use programs 
and independent studies, rFVIIa at the dose of $90 \mu \mathrm{g} / \mathrm{kg}$ appears to be the standard dose commonly used among patients. A 2-hour interval is applied for the first 24 to 48 hours and thereafter increases to 3 to 6 hours according to the severity of bleeding manifestation, efficacy of bleeding control, and relief of pain. This regimen can also be applied for minor and major surgeries; however, a higher initial dose of 120 to $180 \mu \mathrm{g} / \mathrm{kg}$ is required for the major surgery. In cases of unexpected bleeding, increasing the dose of rFVIIa is suggested. Since some patients may have a shorter half-life of rFVIIa (normal children 1.32 hours and normal adult 2.72 hours) and a higher clearance rate (normal children $67.0 \mathrm{~mL} / \mathrm{kg} / \mathrm{h}$ and normal adult $32.8 \mathrm{~mL} / \mathrm{kg} / \mathrm{h}),{ }^{84,85}$ they will require a higher dose (200-300 $\mu \mathrm{g} / \mathrm{kg})$ of rFVIIa to achieve the proper clinical response. A neurosurgical resection of a malignant glioneuronal tumor was reported by giving a bolus of $270 \mu \mathrm{g} / \mathrm{kg}$ every 2 hours during the first 24 hours, followed by $180 \mu \mathrm{g} / \mathrm{kg}$ every 3,4 , and 6 hours at days 2 to 3,4 to 10 , and 11 to 15 , respectively. ${ }^{86}$ Therefore, it should be noted that the optimal dose of rFVIIa depends upon individual half-life and clearance rate of rFVIIa as well as the surgical procedure and bleeding sites. Moreover, elective surgery should be deferred until the inhibitor level is $<5 \mathrm{BU}$, and may require the use of high doses of factor VIII or IX concentrates in cases of uncontrolled intraoperative or postoperative bleeding complications.

The earlier the treatment is given, the more effective will be the outcome. The most effective early treatment is for home treatment programs. The dose of rFVIIa of $90 \mu \mathrm{g} / \mathrm{kg}, 3$ times, 3 hours apart is as effective as a single dose of $270 \mu \mathrm{g} / \mathrm{kg}$. The single dose is convenient especially among pediatric age groups who are needle phobic and have poor venous access. One study has demonstrated the efficacy of effective bleeding control of rFVIIa at the dose of $>200 \mu \mathrm{g} / \mathrm{kg}$ for mild to moderate bleeding at the muscle and joint compared with $<200 \mu \mathrm{g} / \mathrm{kg} .{ }^{32}$

In cases of prophylaxis, the dose of rFVIIa ranging from 200 to $250 \mu \mathrm{g} / \mathrm{kg} /$ week to 90 to $270 \mu \mathrm{g} / \mathrm{kg}$ daily or every 6 to 12 hours has been reported. It is an option for preventing joint bleeding and protecting joint damage before the initiation of immune tolerance therapy. Recombinant factor VIIa is selected due to the awareness of the anamnestic response provoked by residual factor VIII antigen contained in aPCC. However, the number of patients receiving prophylaxis is rather small. Further studies on the most appropriate dose and with a larger number of enrolled subjects are warranted.

Interestingly, the incidence of TE events among hemophilia patients with inhibitors receiving on-label $\mathrm{rFVIIa}$ is extremely low, much less than $1 \%$. The analysis of such TE events from rFVIIa was complicated by the limited data on concomitant and underlying disease risk factors. However, the sequential and concomitant therapy of rFVIIa and aPCC should be given with caution. Further, clinical manifestations and laboratory investigations should be closely monitored by hematology experts in the comprehensive hemophilia center setting.

The only constraint is the cost of rFVIIa to cover bleeding episodes, surgery and prophylaxis for patients with inhibitors, which much higher than for patients without inhibitors. However, it has a very low risk, and is convenient and cost-effective in the long term. It will improve the physical function and functional status of patients. The cost of treating subsequent bleeding episodes at the target joints and other related joints, deformity and disability in the following years should be included in the budget calculation. A hypothetical model of a hemophilia patient after receiving joint replacement with an expected reduction in frequency of bleeding of $80 \%$ from the assumed 12 bleeding episodes per year for 5 years showed that the cost of utilizing rFVIIa was cost-effective. ${ }^{87}$ Moreover, the health related quality of life, psychosocial aspects and self-esteem of the patients as well as their family members should be included in the cost-effectiveness evaluation.

\section{Conclusion}

Recombinant factor VIIa has opened a new era of effective treatment for hemophilia patients with inhibitors worldwide. Hemostasis for bleeding episodes, surgery and prophylaxis has been successfully accomplished. The only constraint is the extremely high cost of medication. However, it is costeffective if the subsequent bleeding episodes at the target joints and other related joints, deformity, disability, and poor health-related quality of life over the next several years are considered in the evaluation.

\section{Acknowledgment}

The study was supported by the Thailand Research Fund-Senior Research Scholar 2006 (A.C.).

\section{Disclosures}

Ampaiwan Chuansumrit and Pantep Angchaisuksiri have received honoraria for speaking at conferences supported by Novo Nordisk and Baxter. Nongnuch Sirachainan stated that she had no interest which might be perceived as posing a conflict or bias. 


\section{References}

1. Lusher JM, Arkin S, Abildaard CF, et al. Recombinant factor VIII for the treatment of previously untreated patients with hemophilia A: a 3.5 year observational study of safety, efficacy and inhibitor development. $N$ Engl J Med. 1993;328:453-459.

2. Ehrenforth S, Kreuz W, Scharrer I, et al. Incidence of development of factor VIII and factor IX inhibitors in haemophiliacs. Lancet. 1992;339:594-598.

3. Briet E. Factor IX inhibitors in hemophilia B patients: their incidence and prospects for development with high purity factor IX products. Blood Coagul Fibrinolysis. 1991;2(Suppl 1):47-50.

4. Roosendaal G, Lafeber FP. Pathogenesis of haemophilic arthropathy. Haemophilia. 2006;12(Suppl 3):117-121.

5. Gringeri A, Mantovani LG, Scalone L, et al. Cost of case and quality of life for patients with hemophilia complicated by inhibitors: the COCIS Study Group. Blood. 2003;102:2358-2363.

6. Hedner U, Kisiel W. Use of human factor VIIa in the treatment of two hemophilia A patients with high-titer inhibitors. J Clin Invest. 1983;71:1836-1841.

7. Hedner U, Ingerslev J. Clinical use of recombinant FVIIa (rFVIIa). Transfus Sci. 1998;19:163-176.

8. Shapiro AD, Gilchrist GS, Hoots WK, et al. Prospective, randomised trial of two doses of rFVIIa (NovoSeven) in haemophilia patients with inhibitors undergoing surgery. Thromb Haemost. 1998;80:773-778.

9. Hedner U. Mechanism of action, development and clinical experience of recombinant FVIIa. J Biotechnol. 2006;124:747-757.

10. Van't Veer C, Golden NJ, Mann KG. Inhibition of thrombin generation by the zymogen factor VII: implications for the treatment of hemophilia A by factor VIIa. Blood. 2000;95:1330-1335.

11. Glazer S, Hedner U, Falch JF. Clinical update on the use of recombinant factor VII, in inhibitors to coagulation factors. In: Aledort LM, Hoyer LW, Lusher JM, Reisner HM, White GC, (editors), Advances in Experimental Medicine and Biology. New York: Plenum Press; 1995;368:163-174.

12. Lusher JM. Recombinant factor VIIa (NovoSeven) in the treatment of internal bleeding in patients with factor VIII and IX inhibitors. Haemostasis. 1996;26(Suppl 1):124-130.

13. Arkin S, Cooper HA, Hutter JJ, et al. Activated recombinant human coagulation factor VII therapy for intracranial hemorrhage in patients with hemophilia A or B with inhibitors. Haemostasis. 1998;28:93-98.

14. Arkin S, Blei F, Fetten J, et al. Human coagulation factor FVIIa (recombinant) in the management of limb-threatening bleeds unresponsive to alternative therapies: results from the NovoSeven emergency-use programme in patients with severe haemophilia or with acquired inhibitors. Blood Coagul Fibrinolysis. 2000;11:255-259.

15. Bech RM. Recombinant factor VIIa in joint and muscle bleeding episodes. Haemostasis. 1996;26(Suppl 1):135-138.

16. Rice KM, Savidge GF. NovoSeven (recombinant factor VIIa) in central nervous system bleeds. Haemostasis. 1996;26(Supp1 1):131-134.

17. Scharrer I. Recombinant factor VIIa for patients with inhibitors of factor VIII or IX or factor VII deficiency. Haemophilia. 1999;5:253-259.

18. Lusher JM, Roberts HR, Davignon G, et al. A randomized, double-blind comparison of two dosage levels of recombinant factor VIIa in the treatment of joint, muscle and mucocutaneous haemorrhages in persons with haemophilia A and B, with and without inhibitors. Haemophilia. 1998;4:790-798.

19. Nilsson IM, Berntorp E, Lofqvist T, et al. Twenty-five years' experience of prophylactic treatment in severe haemophilia A and B. J Intern Med. 1992;232:25-32.

20. Santagostino E, Gringeri A, Mannucci PM. Home treatment with recombinant activated factor VII in patients with factor VIII inhibitors: the advantages of early intervention. Br J Haematol. 1999;104:22-26.

21. Key NS, Aledort LM, Beardsley D, et al. Home treatment of mild to moderate bleeding episodes using recombinant factor VIIa (NovoSeven) in haemophiliacs with inhibitors. Thromb Haemost. 1998;80: 912-918.
22. Ingerslev J, Thykjaer H, Scheibel E. Approaches towards successful home treatment in patients with inhibitors. Eur J Haematol. 1998;61(Suppl 63):11-14.

23. Lusher JM. Acute hemarthroses: the benefits of early versus late treatment with recombinant activated factor VII. Blood Coagul Fibrinolysis. 2000;11(Suppl 1):S45-S49.

24. Lusher JM. Recombinant activated factor VII for treatment of intramuscular haemorrhages: a comparison of early versus late treatment. Blood Coagul Fibrinolysis. 1998;9(Suppl 1):S111-S114.

25. Kavakli K, Makris M, Zulfikar B, et al. Home treatment of haemarthroses using a single dose regimen of recombinant activated factor VII in patients with haemophilia and inhibitors. A multi-centre, randomised, double-blind, cross-over trial. Thromb Haemost. 2006;95:600-605.

26. Young G, Shafer FE, Rojas P, et al. Single $270 \mu \mathrm{g} \mathrm{kg}^{-1}$-dose rVIIa vs standard $90 \mu \mathrm{g} \mathrm{kg}^{-1}$-dose rVIIa and APCC for home treatment of joint bleeds in haemophilia patients with inhibitors: a randomized comparison. Haemophilia. 2008;14:287-294.

27. Santagostino E, Mancuso ME, Rocino A, et al. A prospective randomized trial of high and standard dosages of recombinant factor VIIa for treatment of hemarthroses in hemophiliacs with inhibitors. $J$ Thromb Haemost. 2006;4:367-371.

28. Chuansumrit A, Sriudomporn N, Srimuninnimit V, et al. A single high dose of recombinant factor VIIa combining adjuvant therapy for controlling bleeding episodes in haemophiliacs with inhibitors. Haemophilia. 2001;7:532-536.

29. Chuansumrit A, Sirachainan N, Pakakasama S, et al. Efficacy of different doses of recombinant activated factor VII in the treatment of haemophilia children with inhibitor. Haemophilia. 2008;14:1143-1144.

30. Pan-Petesch B, Laguna P, Mital A, et al. Single dose $\left(270 \mu \mathrm{g} \mathrm{kg}^{-1}\right)$ recombinant activated factor VII for the treatment and prevention of bleeds in haemophilia A patients with inhibitors: experience from seven European haemophilia centres. Haemophilia. 2009;15:760-765.

31. Salaj P, Brabec P, Penka M, et al. Effect of rFVIIa dose and time to treatment on patients with haemophilia and inhibitors: analysis of HemoRec registry data from the Czech Republic. Haemophilia. 2009;15:752-759.

32. Parameswaran R, Shapiro AD, Gill JC, et al. Dose effect and efficacy of rFVIIa in the treatment of haemophilia patients with inhibitors: analysis from the Hemophilia and Thrombosis Research Society Registry. Haemophilia. 2005;11:100-106.

33. Kenet G, Lubetsky A, Luboshitz J, et al. A new approach to treatment of bleeding episodes in young hemophilia patients: a single bolus megadose of recombinant activated factor VII (NovoSeven ${ }^{\circledR}$ ). JThromb Haemost. 2003;1:450-455.

34. Astermark J, Donfield SM, DiMichele DM, et al. A randomized comparison of bypassing agents in hemophilia complicated by an inhibitor: the FEIBA NovoSeven Comparative (FENOC) Study. Blood. 2007;109:546-551.

35. Treur MJ, Mccracken F, Heeg B, et al. Efficacy of recombinant activated factor VII vs activated prothrombin complex concentrate for patients suffering from haemophilia complicated with inhibitors: a Bayesian meta-regression. Haemophilia. 2009;15:420-436.

36. Knight C, Dano AM, Kennedy-Martin T. A systematic review of the cost-effectiveness of rFVIIa and APCC in the treatment of minor/ moderate bleeding episodes for haemophilia patients with inhibitors. Haemophilia. 2009;15:405-419.

37. Chuansumrit A, Isarangkura P, Angchaisuksiri P, et al. Controlling acute bleeding episodes with recombinant factor VIIa in haemophiliacs with inhibitor: continuous infusion and bolus injection. Haemophilia. 2000;6:61-65.

38. Tagariello G, De Biasi E, Gajo GB, et al. Recombinant FVIIa (NovoSeven) continuous infusion and total hip replacement in patients with haemophilia and high titre of inhibitors to FVIII: experience of two cases. Haemophilia. 2000;6:581-583.

39. Montoro JB, Altisent C, Pico M, et al. Recombinant factor VIIa in continuous infusion during central line insertion in a child with factor VIII high-titre inhibitor. Haemophilia. 1998;4:762-765. 
40. Lorenzo JI, Montoro JM, Aznar JA. Postoperative use of rFVIIa by continuous infusion in a haemophilic boy. Haemophilia. 1999;5:135-138.

41. Tagariello G, Bisson R, Radossi P, et al. Concurrent total hip and knee replacements in a patient with haemophilia with inhibitors using recombinant factor VIIa by continuous infusion. Haemophilia. 2003;9:738-740.

42. Schulman S, Bech Jensen M, Varon D, et al. Feasibility of using recombinant factor VIIa in continuous infusion. Thromb Haemost. 1996;75:432-436.

43. Smith MP, Ludlam CA, Collins PW, et al. Elective surgery on factor VIII inhibitor patients using continuous infusion of recombinant activated factor VII: plasma factor VII activity of $10 \mathrm{IU} / \mathrm{ml}$ is associated with an increased incidence of bleeding. Thromb Haemost 2001;86:949-953.

44. Santagostino E, Morfini M, Rocino A, et al. Relationship between factor VII activity and clinical efficacy of recombinant factor VIIa given by continuous infusion to patients with factor VIII inhibitors. Thromb Haemost. 2001;86:954-958.

45. Hedner U. Dosing and monitoring NovoSeven treatment. Haemostasis. 1996;26(Suppl 1):102-108.

46. Ludlam CA, Smith MP, Morfini M, et al. A prospective study of recombinant activated factor VII administered by continuous infusion to inhibitor patients undergoing elective major orthopaedic surgery: a pharmacokinetic and efficacy evaluation. $\mathrm{Br}$ J Haematol. 2003;120:808-813.

47. Ewenstein BM. Continuous infusion of recombinant factor VIIa: continue or not? Thromb Haemost. 2001;86:942-944.

48. Mauser-Bunschoten EP, Koopman MM, Goede-Bolder AD, et al. Efficacy of recombinant factor VIIa administered by continuous infusion to haemophilia patients with inhibitors. Haemophilia. 2002;8:649-656.

49. Perez R, Martinez RL, Pinero A, et al. Sequential treatment with bolus and continuous infusion of recombinant factor VIIa for hip arthroplasty in a patient with haemophilia A and inhibitor. Haemophilia 2002;8:822-825.

50. Baudo F, Redaelli R, Caimi TM, et al. The continuous infusion of recombinant activated factor VIIa (rFVIIa) in patients with factor VIII inhibitors activates the coagulation and fibrinolytic systems without clinical complications. Thromb Res. 2000;99:21-24.

51. Schulman S, d'Oiron R, Martinowitz U, et al. Experiences with continuous infusion of recombinant activated factor VII. Blood Coagul Fibrinolysis. 1998;9(Suppl 1):S97-S101.

52. Rodriguez-Merchan EC, Rocino A, Ewenstein B, et al. Consensus perspectives on surgery in haemophilia patients with inhibitors: summary statement. Haemophilia. 2004;10(Suppl 2):50-52.

53. Hedner U, Glazer S, Pingel K, et al. Successful use of rFVIIa in a patient with severe haemophilia during synovectomy. Lancet. 1988;2:1193.

54. Ingerslev J, Friedman D, Gastineau D, et al. Major surgery in haemophilia patients with inhibitors using recombinant factor VIIa Haemostasis. 1996;26(Suppl 1):118-123.

55. Rodriguez-Merchan EC, Wiedel JD, Wallny T, et al. Elective orthopedic surgery for hemophilia patients with inhibitors: new opportunities. Semin Hematol. 2004;41(Suppl 1):109-116.

56. O’Connell N, Chen J, Byrne M, O’Shea E, Smyth H, Smith OP. Massive pseudotumor resection with recombinant factor VIIa (NovoSeven) cover. Br J Haematol. 2002;116:645-648.

57. Saba HI, Morelli GA, Azam RR, et al. Efficacy of NovoSeven ${ }^{\circledR}$ during surgery on a haemophiliac with previous history of inhibitors. Haemophilia. 2003;9:131-136.

58. Rocino A, Carola A, Papa ML, et al. Major surgery for a gastric cancer in a haemophilic with high inhibitor titre successfully performed by the use of recombinant FVIIa. Haemophilia. 1999;5:441-444.

59. Scharrer I. Recombinant factor VIIa for patients with inhibitors to factor VIII or IX or factor VII deficiency. Haemophilia. 1999;5:253-259.

60. O'Connell N, McMahon C, Smith J, et al. Recombinant factor VIIa in the management of surgery and acute bleeding episodes in children with haemophilia and high responding inhibitors. $\mathrm{Br} J$ Haematol. 2002;116:632-635.
61. Quintana-Molina M, Martinez-Bahamonde F, Gonzalez-Garcia E, et al. Surgery in haemophilic patients with inhibitor: 20 years of experience. Haemophilia. 2004;10(Suppl 2):30-40.

62. Giangrande PLF, Wilde JT, Madan B, et al. Consensus protocol for the use of recombinant activated factor VII [eptacog alfa (activated); NovoSeven ${ }^{\circledR}$ ] in elective orthopaedic surgery in haemophilia patients with inhibitors. Haemophilia. 2009;15:501-508.

63. Lyseng-Williamson KA, Plosker GI. Recombinant factor VIIa (eptacog alfa): A pharmacoeconomic review of its use in haemophilia patients with inhibitors to clotting factors VIII or IX. Pharmacoeconomics. 2007;25:1007-1029.

64. Key NS, Christie B, Henderson N, et al. Possible synergy between recombinant factor VIIa and prothrombin complex concentrate in hemophilia therapy. Thromb Haemost. 2002;88:60-65.

65. Scheiderman J, Nugent DJ, Young G. Sequential therapy with activated prothrombin complex concentrate and recombinant factor VIIa in patients with severe haemophilia and inhibitors. Haemophilia. 2004; 10:347-351.

66. Scheiderman J, Rubin E, Nugent DJ, et al. Sequential therapy with activated prothrombin complex concentrate and recombinant factor VIIa in patients with severe haemophilia and inhibitors: update of our previous experience. Haemophilia. 2007;13:244-248.

67. Chuansumrit A, Husapadol S, Wongwerawattanakoon P, Hongeng S, Sirachainan N, Pakakasama S. Rituximab as an adjuvant therapy to immune tolerance in a haemophilia A boy with high inhibitor titre. Haemophilia. 2007;13:108-110.

68. Martinowitz U, Livnat T, Zivelin A, et al. Concomitant infusion of low doses of rFVIIa and FEIBA in haemophilia patients with inhibitors. Haemophilia. 2009;15:904-910.

69. Cooper HA, Jones CP, Campion E, et al. Rationale for the use of high dose rFVIIa in a high-titre inhibitor patient with hemophilia B during major orthopaedic procedures. Haemophilia. 2001;7:517-522.

70. Saxon BR, Shanks D, Jory CB, et al. Effective prophylaxis with daily recombinant factor VIIa (rFVIIa-NovoSeven) in a child with high titre inhibitors and a target joint. Thromb Haemost. 2001;86:1126-1127.

71. Young G, McDaniel M, Nugent DJ. Prophylactic recombinant factor VIIa in haemophilia patients with inhibitors. Haemophilia. 2005;11:203-207.

72. Konkle BA, Ebbesen LS, Erhardtsen E, et al. Randomized, prospective clinical trial of recombinant factor VIIa for secondary prophylaxis in hemophilia patients with inhibitors. J Thromb Haemost. 2007;5: 1904-1913.

73. Morfini M, Auerswald G, Kobelt RA, et al. Prophylactic treatment of haemophilia patients with inhibitors: clinical experience with recombinant factor VIIa in European Haemophilia Centers. Haemophilia. 2007; 13:502-507.

74. Jimenez-Yuste V, Quintana M, Alvarez MT, et al. Primary prophylaxis with rFVIIa in a patient with severe haemophilia A and inhibitor. Blood Coagul Fibrinolysis. 2008;19:719-720.

75. Jimenez-Yuste V, Alvarez MT, Martin-Salces M, et al. Prophylaxis in 10 patients with severe haemophilia A and inhibitor: different approaches for different clinical situations. Haemophilia. 2009;15:203-209.

76. Hedner U. Potential role of recombinant factor FVIIa in prophylaxis in severe hemophilia patients with inhibitors. J Thromb Haemost. 2006;4:2498-2450.

77. Hoot WK, Erbesen LS, Konkle BA, et al. Secondary prophylaxis with recombinant activated factor VII improves health-related quality of life of haemophilia patients with inhibitors. Haemophilia. 2008;14:466-475.

78. Mannucci PM, Palhares de Miranda PA. International survey of attitudes towards secondary prophylaxis with recombinant factor VIIa in haemophilia patients with inhibitors. Haemophilia. 2009;15:345-347.

79. Abshire T, Kenet G. Recombinant factor VIIa: review of efficacy, dosing regimens and safety in patients with congenital and acquired factor VIII or IX inhibitors. J Thromb Haemost. 2004;2:899-909.

80. Abshire T, Kenet G. Safety update on the use of recombinant factor VIIa and the treatment of congenital and acquired deficiency of factor VIII or IX with inhibitors. Haemophilia. 2008;14:898-902. 
81. Aledort LM. Comparative thrombotic event incidence after infusion of recombinant factor VIIa versus factor VIII inhibitor bypass activity. J Thromb Haemost. 2004;2:1700-1708.

82. O'Connell KA, Wood JJ, Wise RP, et al. Thromboembolic adverse events after use of recombinant human coagulation factor VIIa. JAMA. 2006;295:293-298.

83. Rosenfeld SB, Watkinson KK, Thompson BH, et al. Pulmonary embolism after sequential use of recombinant factor VIIa and activated prothrombin complex concentrate in a factor VIII inhibitor. Thromb Haemost. 2002;87:925-926.

84. Lindley CM, Sawyer WT, Macik BG, et al. Pharmacokinetics and pharmacodynamics of recombinant factor VIIa. Clin Pharmcol Ther. 1994;55:638-648.
85. Hedner U, Kristensen H, BerntorpE, et al. Pharmacokinetics of rFVIIa in children [abstract]. Haemophilia. 1998;4:355.

86. Aouba A, Dezamis E, Sermet A, et al. Uncomplicated neurosurgical resection of a malignant glioneuronal tumor under haemostatic cover of rFVIIa in a severe haemophilia patient with a high-titre inhibitor: a case report and literature review of rFVIIa use in a major surgeries. Haemophilia. 2009 [Epub ahead of print]. http://www.ncbi.nlm.nib. gov/sites/entrez. DOI:10.1111/j.1365-2516.2009. 02089.x.

87. Green C, de Cock E. Cost-consequences of orthopaedic surgery in haemophilia patients with inhibitors. Value Health. 2001;4:467-468.

Journal of Blood Medicine

\section{Publish your work in this journal}

The Journal of Blood Medicine is an international, peer-reviewed, open access, online journal publishing laboratory, experimental and clinical aspects of all topics pertaining to blood based medicine including but not limited to: Transfusion Medicine; Blood collection, Donor issues, Transmittable diseases, and Blood banking logistics; Immunohematology; Artificial and alternative

\section{Dovepress}

blood based therapeutics; Hematology; Biotechnology/nanotechnology of blood related medicine; Legal aspects of blood medicine; Historical perspectives. The manuscript management system is completely online and includes a very quick and fair peer-review system. Visit http://www.dovepress.com/ testimonials.php to read real quotes from published authors.

Submit your manuscript here: http://www.dovepress.com/Journal-of-blood-medicine-journal 